\title{
PCR coupled to electrospray ionization mass spectrometry for microbiological diagnosis and surveillance of ventilator-associated pneumonia
}

\author{
DONGNI HOU ${ }^{1,2^{*}}$, MOHAN JU $^{3 *}$, YING WANG ${ }^{4 *}$, DONGHUI ZHANG ${ }^{1,2}$, DUMING ZHU ${ }^{4}$, \\ MING ZHONG ${ }^{4}$, CHENJUN ZHOU ${ }^{1}$, YUANLIN SONG ${ }^{1,2,5,6}$ and XUNJIA CHENG ${ }^{7}$ \\ ${ }^{1}$ Department of Pulmonary Medicine; ${ }^{2}$ Shanghai Respiratory Research Institute, Zhongshan Hospital, \\ Fudan University, Shanghai 200032; ${ }^{3}$ Institute of Antibiotics, Huashan Hospital, Fudan University, Shanghai 200040; \\ ${ }^{4}$ Department of Critical Care Medicine, Zhongshan Hospital, Shanghai 200032; ${ }^{5}$ Department of Pulmonary \\ Medicine, Zhongshan Hospital, Qingpu Branch, Shanghai 201700; ${ }^{6}$ National Clinical Research Center for Aging and \\ Medicine, Huashan Hospital, Shanghai 200040; ${ }^{7}$ Department of Medical Microbiology and Parasitology, Institute \\ of Biomedical Sciences, School of Basic Medical Sciences, Fudan University, Shanghai 200032, P.R. China
}

Received August 7, 2019; Accepted March 2, 2020

DOI: $10.3892 / \mathrm{etm} .2020 .9103$

\begin{abstract}
Etiological diagnosis is essential for anti-infective therapy in patients with ventilator-associated pneumonia (VAP). The present study aimed to evaluate the capacity of sequential PCR coupled to electrospray ionization mass spectrometry (PCR/ESI-MS) tests as a rapid diagnostic technique for patients with VAP. A total of 12 patients diagnosed with VAP were enrolled at the intensive care unit in Zhongshan Hospital, Fudan University. Mini-bronchoalveolar lavage fluid specimens were prospectively collected on VAP 0,5 and 10 days following the beginning of mechanical ventilation. Routine clinical culture and PCR/ESI-MS were compared for identification of microorganisms in the specimens. A
\end{abstract}

Correspondence to: Professor Yuanlin Song, Department of Pulmonary Medicine, Zhongshan Hospital, Fudan University, 180 Fenglin Road, Shanghai 200032, P.R. China

E-mail: ylsong70@163.com

Professor Xunjia Cheng, Department of Medical Microbiology and Parasitology, Institute of Biomedical Sciences, School of Basic Medical Sciences, Fudan University, 131 Dong'an Road, Shanghai 200032, P.R. China

E-mail: xjcheng@shmu.edu.cn

*Contributed equally

Abbreviations: VAP, ventilator-associated pneumonia; ICU, intensive care unit; PCR/ESI-MS, PCR coupled to electrospray ionization mass spectrometry; $\mathrm{MV}$, mechanical ventilation; mini-BALF, mini-bronchoalveolar lavage fluid

Key words: respiration, artificial, electrospray ionization mass spectrometry, nosocomial infection, microbiological techniques, diagnosis total of 51 bacterial species were detected by either of the two methods. The positive rates of routine clinical culture and PCR/ESI-MS were 38.2 and $88.2 \%$, respectively. Out of the 16 specimens positive in routine cultures, 15 were also positive on PCR/ESI-MS, except for one, from which a mix of three distinct bacterial isolates were reported by culture. Among the 50 bacterial species identified by PCR/ESI-MS, $15(35.7 \%)$ of the common VAP pathogens were confirmed by paired culture. Furthermore, of the 16 bacterial isolates that were finally confirmed to be responsible for VAP, 14 were identified by a sequential PCR/ESI-MS test concurrently when the culture results were obtained. PCR/ESI-MS identified pathogens that may cause VAP in 8 subjects prior to the occurrence of associated clinical manifestations. To conclude, PCR/ESI-MS was a potential rapid technique for diagnosis of VAP within $6 \mathrm{~h}$. Regular respiratory specimen monitoring using PCR/ESI-MS provides information for selecting appropriate and adequate antibiotic therapies in ventilated patients.

\section{Introduction}

Ventilator-associated pneumonia (VAP) is a common nosocomial infection in patients who require mechanical ventilation in intensive care units (ICUs). VAP is associated with increased mortality, prolonged hospital stay and an increased economic burden (1-3). Inappropriate therapy and delayed initiation of appropriate therapy may lead to increased patient mortality (4).

Guidelines recommend instant empirical antibiotic therapy after the diagnosis of VAP (5). Therapy choices for initial antibiotics are mainly based on the local antibiogram, risk factors for multiple drug-resistant infections and the onset time of VAP. Intensive and combined initial therapy and de-escalating therapy are recommended for VAP. Of note, administration of inappropriate initial antibiotics may lead to failure to protect against multiple drug-resistant microbes and may also select for multiple drug-resistant strains. Determining the aetiology 
of VAP is therefore important for initial antibiotic treatment and therapy adjustment.

Novel DNA-based molecular techniques for microorganism detection have been reported as alternative tools for the aetiological diagnosis of bacteraemia and respiratory infections. Conventional laboratory culture generally takes 2-3 days for testing and has a positive rate influenced by numerous factors. Early recognition and subsequent appropriate antibiotic therapy are beneficial. Existing diagnostic approaches delay the start of targeted antibiotic therapy and result in unnecessary antibiotic exposure. PCR coupled to electrospray ionization mass spectrometry (PCR/ESI-MS) is a novel tool that provides automatic, rapid and high-throughput pathogen detection and has been proven successful in identifying bacterial and fungal pathogens in clinical infections $(6,7)$. However, whether PCR/ESI-MS is useful for providing an accurate and rapid pathogenic diagnosis for clinical antibiotic therapy in respiratory infections remains controversial.

The aim of the present study was to evaluate the capacity of PCR/ESI-MS to provide a pathogenic diagnosis for patients with VAP in a short time $(<6 \mathrm{~h})$ and to determine whether this technique is able to identify respiratory pathogen alterations in mechanically ventilated (MV) patients to help clinicians choose the appropriate initial empirical therapy when VAP occurs. First, the concordance between PCR/ESI-MS and conventional bacterial culture was investigated for identifying VAP pathogens and subsequently, the correlation between bacterial species identified by the sequential PCR/ESI-MS test and the final pathogenic diagnosis of VAP was examined.

\section{Materials and methods}

Study design. Patients admitted to the surgical ICU of a comprehensive teaching hospital between September 2011 and July 2012 who required mechanical ventilation for $>48 \mathrm{~h}$ were recruited. Patients between 18 and 85 years of age without any infectious disease prior to mechanical ventilation were eligible and were excluded if they had diffuse bronchiectasis, massive haemoptysis, cystic fibrosis or end-stage malignant disease. They were also excluded if they received any antibiotics or immunosuppressive drugs within 1 week of ventilation or if they were pregnant or breast-feeding. A total of 30 subjects were eligible and enrolled in the present study. Of these subjects, 12 were diagnosed with VAP within 2 weeks after MV initiation. The diagnosis of VAP was based on the following criteria: New-onset fever of $>38.5^{\circ} \mathrm{C}$, elevated peripheral blood white cell count $\left(>10 \times 10^{9} / 1\right)$, elevated procalcitonin level, purulent secretions in mini-bronchoalveolar lavage fluid (BALF), new diffuse or localized infiltration in a chest X-ray or CT scan and a decreased ratio of partial pressure of arterial oxygen to the fraction of inspired oxygen of $<240$. Data, including demographic characteristics, initial clinical presentation, laboratory tests, MV parameters and duration, antibiotic therapy management, complications and outcomes, were collected prospectively.

Mini-BALF sampling. Mini-BALF samples were collected from each eligible patient 0,5 and 10 days after MV initiation by qualified doctors using sterile tubes (with a diameter of $5 \mathrm{~mm}$ ) as previously described. The total volume of physiological saline for bronchoalveolar lavage was 10-20 and 7-10 ml of fluid was collected. Each sample was divided equally into two parts: One part was sent for bacterial culture immediately and the other part was stored at $-80^{\circ} \mathrm{C}$. If the patient developed VAP within 10 days after $\mathrm{MV}$, the stored mini-BALF samples were tested using PCR/ESI-MS. In addition to mini-BALF sampling, sputum samples were sent for routine clinical culture when required.

Routine clinical microbiological culture. Clinical cultures for fungi, aerobic bacteria and anaerobic bacteria identification were performed by the hospital laboratory using mini-BALF samples as previously described (8). A culture was defined as positive when bacteria were present at a concentration of $\geq 1 \times 10^{4}$ colony-forming units $(\mathrm{CFU}) / \mathrm{ml}$. Culture results assisted in the therapeutic decision-making of the clinicians.

DNA extraction and PCR/ESI-MS. Total DNA was isolated from centrifuged cells of each mini-BALF sample using the QIAamp DNA Mini kit (cat. no. 51304; Qiagen, Inc.) according to the manufacturer's protocol. PCR/ESI-MS was performed using a PLEX-ID Broad Bacteria Assay plate (Ibis Biosciences, Inc.), which was coated with primers, placed on a plate vibrator at room temperature for $15 \mathrm{~min}$ and then centrifuged at $450 \mathrm{x} \mathrm{g}$ for $1 \mathrm{~min}$. Extracted nucleic acids from mini-BALF samples were loaded into wells in the assay plate $(5 \mu \mathrm{l} /$ well). The broad bacterial assay uses primer pairs designed for amplifying a variable region of common clinical gram-positive and gram-negative bacteria, as well as Candida spp. The assay plates were sealed and centrifuged $(450 \mathrm{x} \mathrm{g}$, $1 \mathrm{~min}, 4^{\circ} \mathrm{C}$ ) before PCR was performed according to the manufacturer's protocol. PCR products were immediately desalted and then submitted to a PLEX-ID system for mass spectral analysis (9). In brief, electrospray ionization moves charged amplicons into a mass spectrometer. Based on the resulting spectrum, base compositions are algorithmically predicted and then compared to a reference database for quantitative identification of bacterial species (10).

PCR/ESI-MS analysis. For each microorganism identified, a Q-score ranging from 0 to 1 was reported by the PLEX-ID system (Abbott Laboratories). The Q-score is calculated using principal component analysis and represents a relative measure of the strength of the data supporting the identification of a certain pathogen. Microorganisms reported by the system were considered to be 'positive' when the Q-score was $\geq 0.8$. 'Positive' results from PCR/ESI-MS were compared to routine cultures (within 30 days) of paired samples as the gold standard (11). The clinical significance of positive results for certain bacteria that were negative in paired culture was evaluated by a microbiologist and an ICU physician who reviewed the medical history and the results of cultures or PCR/ESI-MS of specimens (e.g., nasal swab, throat swab, sputum or mini-BALF within 7 days) from the patient (11).

Management of oral bacterial flora detected in the respiratory tract. Bacterial species identified by culture or PCR/ESI-MS that were clinically regarded as normal respiratory flora (including alpha-haemolytic streptococci, coagulase-negative staphylococci, Neisseria spp., and Candida spp.) were 


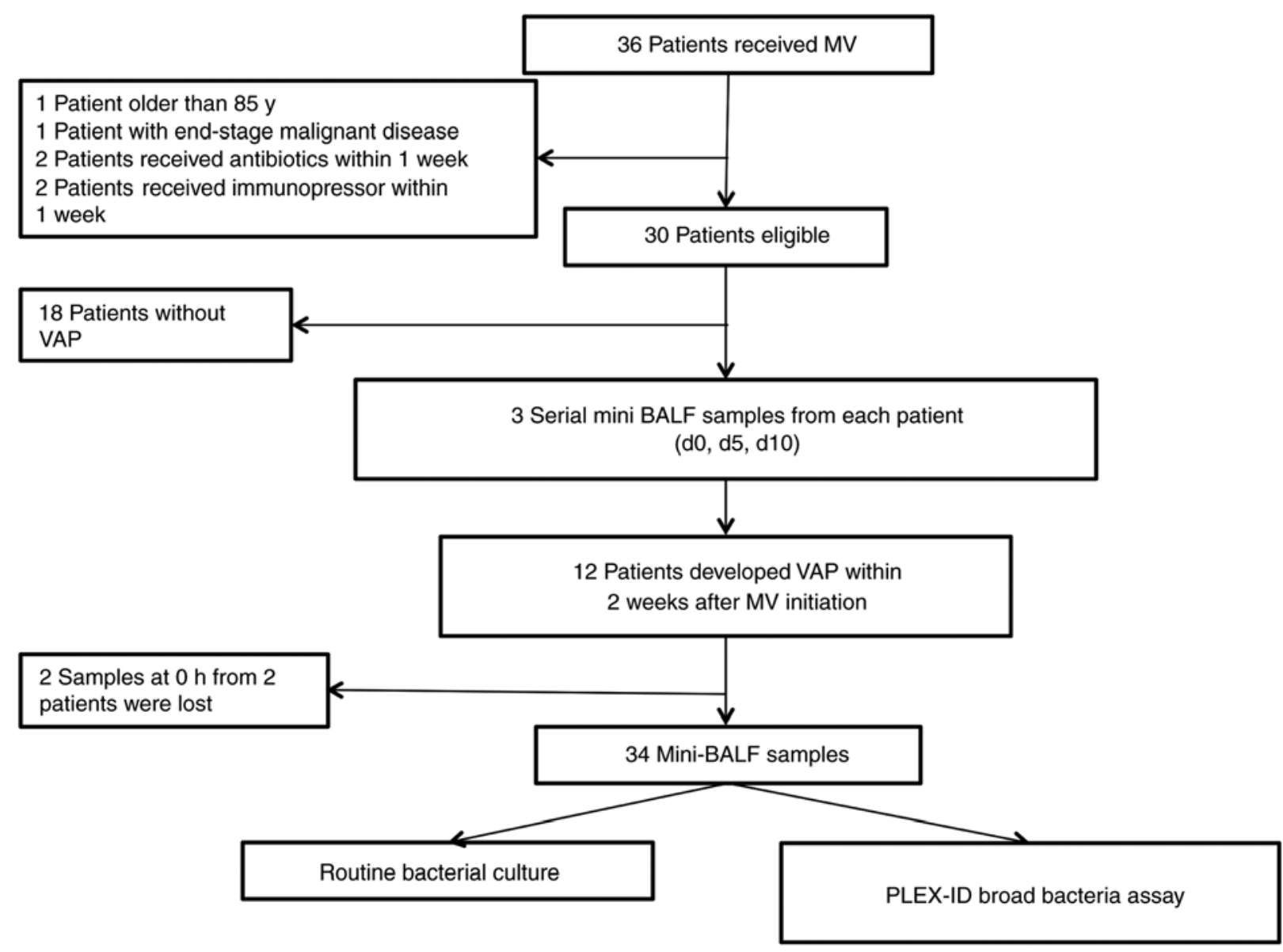

Figure 1. Workflow of the sample collection in the present study. MV, mechanical ventilation; BALF, bronchoalveolar lavage fluid; d, day; y, years; VAP, ventilator-associated pneumonia.

considered to indicate a negative result in the data evaluation process.

Statistical analysis. Data were presented as the \% for categorical variables and as the mean \pm SD or median with interquartile range (25-75\%) for continuous variables. Data were analysed with SPSS version 22.0 (IBM Corp.).

\section{Results}

Demographics and clinical information of subjects diagnosed with VAP. A total of 34 mini-BALF samples from 12 patients diagnosed with VAP within 10 days after MV were analysed in the present study (see workflow chart in Fig. 1). The clinical characteristics of the subjects are summarized in Table I. The mean age of subjects was $62.8 \pm 12.2$ years, and $16.7 \%$ awere female. The most common comorbidities were hypertension and malignant solid tumors.

Agreement of routine clinical culture and PCR/ESI-MS in mini-BALF samples from VAP patients. At the specimen level, the concordance (positive as well as negative) between the two methods was 50\% (17/34). Routine clinical culture identified at least 1 positive isolate in 13 of the 34 mini-BALF specimens (positive rate, $38.2 \%$ ), while the PCR/ESI-MS method detected pathogenic bacteria in 30 of the 34 samples (positive rate, $88.2 \%$ ) according to the criteria for positivity (see Methods section). Of note, all of the positive culture specimens were also identified by PCR/ESI-MS (matched positive: 13/34, 38.2\%) with a positive agreement rate of $100 \%$. However, except for the 4 specimens that were negative by the two methods (matched negative: $4 / 34,11.8 \%$ ), PCR/ESI-MS identified bacteria in 17 culture-negative specimens $(17 / 34,50 \%$; negative agreement rate: 19\%; Table II). These results imply that PCR/ESI-MS was sensitive in identifying bacteria in mini-BALF samples from ventilated patients at the specimen level.

PCR/ESI-MS has high sensitivity for identifying VAP bacteria at the species level. A total of 51 bacterial species were detected in 30 specimens using clinical culture, PCR/ESI-MS or the two methods (Table III). Routine clinical culture identified 16 bacterial isolates $(16 / 51,31.4 \%)$ from 13/34 specimens (Table III). Of these, 15 were also positive on PCR/ESI-MS (positive agreement: 15/16, 93.8\%) and 1 was negative $(1 / 16,6.2 \%)$. The only isolate positive in culture but negative in PCR/ESI-MS was from one of the 8 mixed-infection specimens, which included 3 distinct bacterial isolates, while 2 isolates from another mixed-infection specimen were correctly identified by PCR/ESI-MS. The positive agreements in simple infection and mixed infection were $100 \%$ (11/11) and $80.0 \%$ (4/5), respectively (Table IV), which suggested that PCR/ESI-MS had notable sensitivity and it was indicated that it is able to detect specimens with mixed infections. 
Table I. Clinical characteristics of the patients with VAP $(n=12)$.

\begin{tabular}{lc}
\hline Characteristic & Value \\
\hline Age (years) & $62.8(33-81)$ \\
Female gender & $2(16.7)$ \\
Diagnosis & \\
MT & $4(30.8)$ \\
Esophageal & $3(23.1)$ \\
Colon & $1(7.7)$ \\
Trauma & $2(15.4)$ \\
Gastrointestinal perforation & $2(15.4)$ \\
Others & \\
Comorbidity & $4(30.8)$ \\
Diabetes mellitus & \\
Hypertension & $1(7.7)$ \\
Arrhythmia & $3(23.1)$ \\
Surgery & $1(7.7)$ \\
WBC (10 6 /l) & $10(76.9)$ \\
PCT ( $\mu$ g/l) & $12.98 \pm 5.45$ \\
Chest X-ray & $10.13 \pm 8.85$ \\
Infiltration & \\
Diffuse infiltration & $11(91.7)$ \\
Time-point of VAP diagnosis from & $1(8.3)$ \\
hospitalization (days) & $7(3-22)$ \\
Days of MV & \\
Antibiotics prior to MV & $19.5(10-80)$ \\
Outcome & $5(38.5)$ \\
Discharge & \\
Deceased & $8(62)$ \\
\hline Dalues are & $4(31)$ \\
\hline
\end{tabular}

Values are expressed as $\mathrm{n}(\%)$, mean \pm standard deviation or median

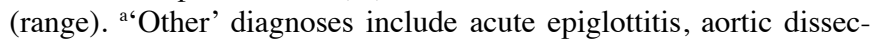
tion, subarachnoid hemorrhage and artery thrombosis. MT, malignant tumor; WBC, white blood cells; MV, mechanical ventilation; PCT, procalcitonin.

PCR/ESI-MS identifies bacteria possibly missed by routine culture. PCR/ESI-MS identified 50 bacterial species from 30 mini-BALF specimens (Table III). As previously mentioned, 15 of them $(15 / 50,30 \%)$ were positive on the two methods. However, the other 35 (35/50, 70\%) detected by PCR/ESI-MS did not produce any positive results in routine culture. It was then assessed whether the bacteria identified only by PCR/ESI-MS had clinical significance, i.e. whether they were false-positive on PCR/ESI-MS or false-negative in routine clinical culture. The results of the routine culture were compared to those of the other two of the three sequential mini-BALF specimens or sputum specimens from the same patient sent by clinicians; 19 of the PCR/ESI-MS-identified bacterial species (19/35, 54.3\%) had positive results according to the clinical criteria (specified in the Methods section) and they represented $38.0 \%$ of all $50 \mathrm{PCR} / \mathrm{ESI}-\mathrm{MS}$ reports. Thus, these bacteria were possibly missed by the routine cultures.
Table II. Concordance of routine clinical culture and PCR/ ESI-MS in mini-bronchoalveolar lavage fluid samples at the specimen level $(n=34)$.

\begin{tabular}{lc}
\hline Concordance & $\mathrm{n}(\%)$ \\
\hline Matched (+) & $13(38.2)$ \\
Matched (-) & $4(11.8)$ \\
Only culture (+) & $0(0)$ \\
Only PCR/ESI-MS (+) & $17(50)$ \\
Overall agreement (\%) & 50 \\
Positive agreement $^{\mathrm{a}}(\%)$ & 100 \\
Negative agreement $^{\mathrm{b}}(\%)$ & 19.0 \\
\hline
\end{tabular}

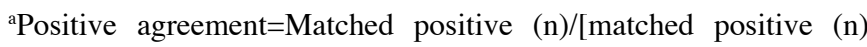

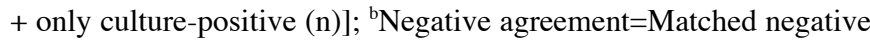
(n)/[matched negative (n) + only culture-negative (n)]. PCR/ESI-MS, PCR coupled to electrospray ionization mass spectrometry.

A total of 16 bacterial species that had positive results on PCR/ESI-MS (16/35, 45.7\% of the bacterial species identified only by PCR/ESI-MS; 16/50, 32\% of the total bacterial species identified by PCR/ESI-MS) were not clinically significant (Table III). Streptococcus pneumoniae $(\mathrm{n}=5)$ and Haemophilus influenzae $(\mathrm{n}=3)$, which are two common pathogens of community-acquired pneumonia and are less likely to cause VAP, represented $50 \%(8 / 16)$ of the bacterial species. In addition, the bacterial species identified only by PCR/ESI-MS and with clinical significance included Pseudomonas aeruginosa $(\mathrm{n}=6)$, Burkholderia spp. $(\mathrm{n}=5)$, Acinetobacter baumannii $(\mathrm{n}=4)$, Klebsiella pneumoniae $(\mathrm{n}=3)$, and Staphylococcus aureus $(\mathrm{n}=1)$. The results suggest that $81.0 \%(34 / 42)$ of the PCR/ESI-MS-identified species were common VAP pathogens with clinical significance in mini-BALF samples of mechanically ventilated patients.

Variations in the pathogenic spectrum in patients during $M V$. It was attempted to track the alterations in bacterial composition in the airways of subjects under MV using two aetiological techniques and their efficiency in terms of providing a quick pathogenic diagnosis was compared. Bacterial species determined by either routine culture or PCR/ESI-MS were used in this longitudinal analysis, while the results from 2 subjects whose specimens were not complete were excluded (Fig. 2). When MV started, there were relatively few positive results for bacteria and the most common species detected were Streptococcus pneumoniae and Pseudomonas aeruginosa. As MV continued, the positive rates of Pseudomonas aeruginosa (7/10) increased significantly and were highest on day 10 , followed by Acinetobacter baumannii (5/10), Staphylococcus aureus (3/10), Burkholderia spp. (3/10) and Klebsiella pneumoniae (2/10). No fungus other than Candida spp., which was classified as normal flora, was detected by either of the two methods. Non-cultivable pathogens, including Legionella pneumophila or Mycoplasma pneumoniae, did not reach the positivity criteria of PCR/ESI-MS, which was possibly due to their low concentration. 
Table III. Bacterial species identified by routine bacterial culture and/or PLEX-ID in 34 mini-bronchoalveolar lavage fluid specimens from 12 patients diagnosed with ventilator-associated pneumonia.

\begin{tabular}{|c|c|c|c|c|}
\hline \multirow[t]{2}{*}{ Bacterial Species } & \multicolumn{4}{|c|}{ Culture/PCR/ESI-MS } \\
\hline & $+/+$ & $+/-$ & $\begin{array}{c}\quad-/+ \\
\text { (With clinical } \\
\text { significance) }\end{array}$ & $\begin{array}{c}-/+ \\
\text { (Without clinical } \\
\text { significance) }\end{array}$ \\
\hline Acinetobacter baumannii/calcoaceticus & 4 & 0 & 4 & 2 \\
\hline Burkholderia ambifaria/vietnamiensis & 0 & 0 & 5 & 1 \\
\hline Enterobacter aerogenes & 1 & 0 & 0 & 0 \\
\hline Enterobacter cloacae & 1 & 0 & 0 & 0 \\
\hline Escherichia coli & 1 & 0 & 0 & 0 \\
\hline Klebsiella pneumoniae & 1 & 0 & 3 & 2 \\
\hline Pseudomonas aeruginosa & 6 & 0 & 6 & 1 \\
\hline Staphylococcus aureus & 1 & 1 & 1 & 2 \\
\hline Haemophilus influenzae & 0 & 0 & 0 & 3 \\
\hline Streptococcus pneumoniae & 0 & 0 & 0 & 5 \\
\hline Total & 15 & 1 & 19 & 16 \\
\hline
\end{tabular}

PCR/ESI-MS, PCR coupled to electrospray ionization mass spectrometry.

Table IV. Concordance of routine clinical culture and PCR coupled to electrospray ionization mass spectrometry for identified bacteria.

\begin{tabular}{|c|c|c|c|}
\hline Concordance & $\begin{array}{c}\text { By bacteria } \\
\text { (all) } \\
(n=51)\end{array}$ & $\begin{array}{c}\text { By bacteria } \\
\text { (simple infection) }^{\mathrm{a}} \\
\mathrm{n}=43\end{array}$ & $\begin{array}{c}\text { By bacteria } \\
{\text { (mixed infection })^{b}}^{b}=8\end{array}$ \\
\hline Matched positive (n) & 15 & 11 & 4 \\
\hline Only culture-positive (n) & 1 & 0 & 1 \\
\hline Only PCR-positive (n) & 35 & 32 & 3 \\
\hline Overall agreement $(\%)$ & 29.4 & 25.6 & 50.0 \\
\hline Positive agreement ${ }^{\mathrm{c}}(\%)$ & 93.8 & 100.0 & 80.0 \\
\hline
\end{tabular}

${ }^{a}$ Simple infection: Specimens containing only 1 bacterial isolate; ${ }^{b}$ Mixed infection: Specimens containing $\geq 1$ bacterial isolates.

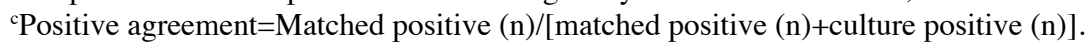

A total of 16 bacteria from 12 subjects were confirmed as pathogens that cause VAP according to mini-BALF or sputum cultures (Table $\mathrm{V}$ ). When the results of sequential PCR/ESI-MS were examined on days 0,5 and 10,7 of the final VAP pathogens were detected by PCR/ESI-MS 5-20 days prior to the report of routine culture; the other 7 VAP pathogens were detected simultaneously from specimens taken on the same day by using the two methods. Only 2 VAP pathogens were detected first by culture of sputum specimens sent by clinicians on days 7 and 8 after the second PCR/ESI-MS test, but the specimens were also positive in the third PCR/ESI-MS test on day 10. Thus, sequential PCR/ESI-MS tests on days 0,5 and 10 were able to identify the pathogens of VAP in certain subjects earlier than routine culture (Table V). Of note, in 8 subjects, PCR/ESI-MS even confirmed VAP pathogens on day 0 and day 5 before any clinical manifestations occurred. These bacteria already existed in the respiratory tract of ventilated subjects in the early days of ventilation and caused pulmonary infection later. By contrast, routine culture predicted such pathogens in only 1 patient. In conclusion, sequential PCR/ESI-MS may not only lead to a pathogenic diagnosis of VAP that is faster than routine culture but also provide references for clinicians to select an appropriate initial antibiotic therapy at the time VAP is diagnosed.

\section{Discussion}

Early and appropriate antibiotic therapy is key to improving outcomes, reducing side effects and lowering treatment costs in patients with VAP. The identification of bacterial isolates from clinical specimens by routine culture usually takes 2-3 days. To overcome the technical delay, novel strategies with high efficiency and sensitivity are required to provide an aetiological diagnosis 
Table V. Time-points of VAP diagnosis and identification VAP pathogens by routine clinical culture and PCR/ESI-MS.

\begin{tabular}{|c|c|c|c|c|}
\hline Case ID & Day of diagnosis ${ }^{\mathrm{a}}$ & Confirmed VAP pathogen ${ }^{\mathrm{b}}$ & Days of positive culture & Day of PCR/ESI-MS positivity \\
\hline A & 4 & Pseudomonas aeruginosa & 10 & 10 \\
\hline $\mathrm{C}$ & 9 & Staphylococcus aureus & 10 & 10 \\
\hline $\mathrm{D}$ & 9 & Pseudomonas aeruginosa & 10 & 0 \\
\hline $\mathrm{E}$ & 5 & Acinetobacter baumannii & 5 & 0 \\
\hline \multirow[t]{2}{*}{$\mathrm{F}$} & 8 & Acinetobacter baumannii & 5 & 5 \\
\hline & & Pseudomonas aeruginosa & 5 & 5 \\
\hline G & 8 & Pseudomonas aeruginosa & 20 & 0 \\
\hline \multirow[t]{2}{*}{ I } & 13 & Burkholderia spp. & 14 & 0 \\
\hline & & Pseudomonas aeruginosa & 17 & 5 \\
\hline $\mathrm{J}$ & 6 & Pseudomonas aeruginosa & 7 & 0 \\
\hline \multirow[t]{3}{*}{$\mathrm{K}$} & 3 & Acinetobacter baumannii & 10 & 10 \\
\hline & & Pseudomonas aeruginosa & 10 & 10 \\
\hline & & Escherichia coli & 10 & 10 \\
\hline $\mathrm{L}$ & 5 & Pseudomonas aeruginosa & 7 & 10 \\
\hline M & 3 & Klebsiella pneumoniae & 10 & 5 \\
\hline $\mathrm{O}$ & 6 & Staphylococcus aureus & 6 & 10 \\
\hline
\end{tabular}

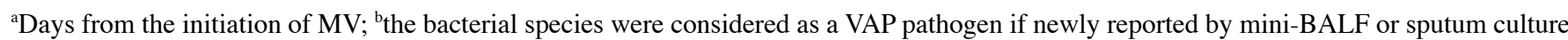
after VAP onset and consistent with the clinical manifestations. PCR/ESI-MS, PCR coupled to electrospray ionization mass spectrometry; VAP, ventilator-associated pneumonia.

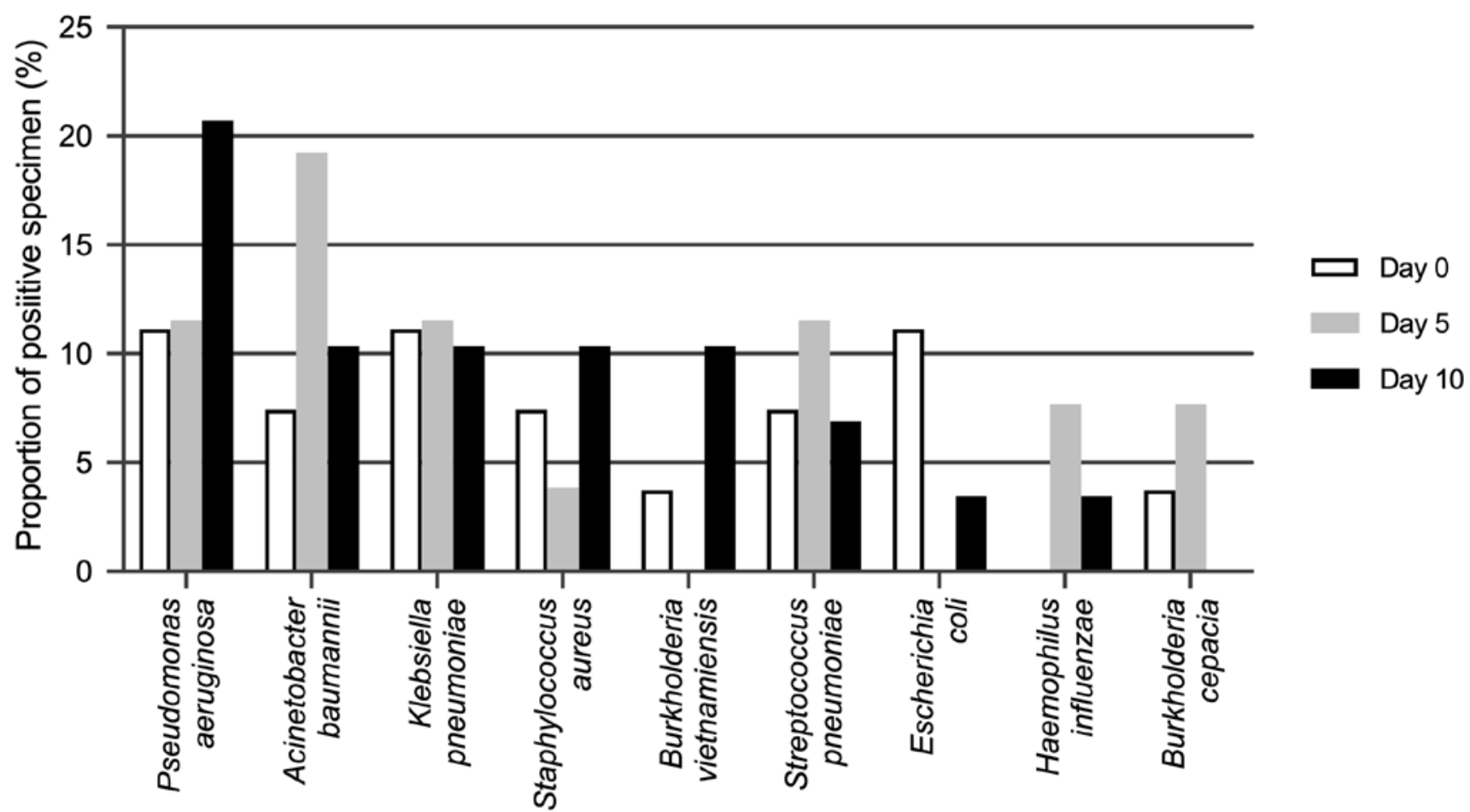

Figure 2. Alterations in bacterial pathogens in patients with VAP identified by PCR/ESI-MS. Mini-BALF samples were collected from 10 subjects diagnosed with VAP at three time-points $(0,5$ and 10 days of mechanical ventilation). Each column indicates the number of mini-BALF samples that were reported to be bacteria-positive at different time-points of VAP. Culture-positive or PCR/ESI-MS-positive samples were included. The columns were grouped by distinct bacterial species, indicating the change in positive rates of each bacterial organism in the mini-BALF of VAP patients. BALF, bronchoalveolar lavage fluid; VAP, ventilator-associated pneumonia; PCR/ESI-MS, PCR coupled to electrospray ionization mass spectrometry.

of VAP. Culture-independent microbiological techniques developed based on PCR have impressive potential in pathogen identification for infectious diseases, particularly life-threatening infections including sepsis, bloodstream infection and pneumonia (12-15). As one of these techniques, PCR/ESI-MS has been reported to improve microbiological detection in blood and respiratory specimens $(11,15,16)$, as well as samples from patients already receiving antibiotics (17). However, in contrast 
to those on blood samples, prospective studies on the clinical value of PCR/ESI-MS for evaluating BALF specimens in patients with suspected VAP are limited.

In the present study, the effectiveness of PCR/ESI-MS in examining mini-BALF samples of patients with suspected VAP was evaluated. The results confirmed the high sensitivity of PCR/ESI-MS in that all routine culture-positive specimens were also positive on PCR/ESI-MS with high accuracy for the bacterial species identified (93\%). Only one exception was observed with a positive culture result paired with a negative PCR/ESI-MS result, which was observed with a sample containing two other species mixed in the same specimen, suggesting that there may be interference from two coexisting bacterial species. Other studies of mini-BALF samples reported a sensitivity of $91.7 \%$ in patients suspected to have VAP (17), and the types of microorganisms identified in $79-100 \%$ of patients with suspected pneumonia or other diseases requiring mini-BALF sampling exhibited a variation $(16,18)$. Certain organisms had a higher 'missed' rate by PCR/ESI-MS, including Pneumocystis jirovecii, Actinomyces odontolyticus and Enterobacter cloacae $(17,18)$, while it was rare that bacterial species that are common pathogens of VAP were missed by PCR/ESI-MS. Thus, a better bacterial detection performance may be achieved by screening particular patient groups, e.g. patients with suspected VAP in whom the causative pathogens are relatively focused. In summary, the good sensitivity and negative predictive value confirmed PCR/ESI-MS to be valuable for ruling out ventilation-associated infection.

In addition to the long time required by routine cultures, the negative results from routine microbiological cultures in patients with suspected VAP remain a challenge for clinicians. Routine cultures tend to be negative when the concentration or activity of microorganisms is low. Treatment with antibiotics prior to sampling affects the sensitivity of the culture. By contrast, PCR-based methods specifically detect nucleic acids in specimens, regardless of the microbial activity. The diagnostic value of PCR-based techniques in culture-negative cases has been reported $(14,19,20)$. According to previous studies, the limit of detection using PCR/ESI-MS was $\sim 16 \mathrm{CFU} / \mathrm{ml}$ and $1 \times 10^{3}$ to $1 \times 10^{4}$ genome copies per $\mathrm{ml}$, indicating that the sensitivity is much higher than that of culture-based quantitative microbiology (21) and matrix-assisted laser desorption ionization-time of flight/MS techniques (9). In the present study, PCR/ESI-MS detected $\geq 1$ bacterial species from $50 \%$ of the total specimens. Further investigation revealed that $68 \%(34 / 50)$ of bacteria only positive on PCR/ESI-MS were confirmed by paired mini-BALF cultures or routine culture of other mini-BALF or sputum specimens from the same patient within 7 days and clinical manifestations. Of note, in contrast to the low positive prediction $(0 / 8)$ of common community acquired pneumonia pathogens (Streptococcus pneumoniae and Haemophilus influenzae), the percentage of common VAP bacteria identified by PCR/ESI-MS was $81 \%(34 / 42)$. It may be speculated that common VAP bacteria detected by PCR/ESI-MS with negative culture results were missed in routine clinical culture despite their proliferation activity and their pathogenicity cannot be confirmed. These results highlight the complementary role of PCR/ESI-MS as an informative microbiological test in patients with suspected VAP, particularly in culture-negative cases.
The present study differs from previous studies, as serial mini-BALF specimens were collected from ventilated patients and compared the microorganisms reported by PCR/ESI-MS prior to the onset of VAP, and the final aetiological diagnosis of VAP was confirmed by routine culture. It was hypothesized that due to its high-throughput feature, PCR/ESI-MS may rapidly detect variations in the respiratory microbiota of ventilated patients; thus, regular monitoring of mini-BALF is able to predict the pathogens that may cause VAP. In the patient cohort, the presence of several bacterial species, including Pseudomonas aeruginosa, Acinetobacter baumannii, and Staphylococcus aureus, was increased and these species were reported to mutually exclude other community members (21). In 10/12 subjects, PCR/ESI-MS reported VAP pathogens no later than routine culture. Of note, in 5 subjects, the final VAP pathogen was identified by PCR/ESI-MS before VAP occurred. The results are consistent with a previous study indicating the presence of a microbiologically positive pathogen burden prior to the clinical diagnosis of VAP (20). Monitoring mini-BALF using highly sensitive methods in ventilated patients may improve patient outcomes.

The present study has certain limitations. First, ventilated patients who did not develop VAP were not included. Thus, it cannot be confirmed whether VAP pathogens detected using PCR/ESI-MS indicate an elevated risk for VAP. Initiation of antibiotic therapy based on the PCR/ESI-MS results in subjects without any manifestations of VAP may lead to overmedication. Further evidence is needed to determine if a prophylactic antibiotic is beneficial in asymptomatic ventilated patients with highly pathogenic species detectted in BALF by PCR/ESI-MS. Second, pathogen isolation by routine microbiological cultures is regarded as the gold standard, however, it is not very sensitive. Some pathogens detected by RT-PCR/ESI-MS specimens detected by could not be confirmed or thoroughly ruled out. Furthermore, the PCR/ESI-MS tests were performed together at the end of the study, and therefore, it was not possible to observe the possible benefits of rapid PCR/ESI-MS reports. Additional prospective studies are required to evaluate its effects on clinical outcomes.

In conclusion, PCR/ESI-MS has the potential to accelerate the aetiological diagnosis of VAP within $6 \mathrm{~h}$ and predict the bacterial species that tend to cause VAP prior to clinical diagnosis. Regular respiratory specimen monitoring using PCR/ESI-MS has possible clinical benefits for ventilated subjects by guiding appropriate and adequate initial antibiotic therapy to achieve better outcomes and decrease the use of broad-spectrum antibiotics to reduce costs and side effects.

\section{Acknowledgements}

The authors would like to thank Ms. Cuicui Chen, Dr Linlin Wang and Dr Nana Feng (Department of Pulmonary and Critical Care Medicine, Zhongshan Hospital, Fudan University, Shanghai, China) for data collection.

\section{Funding}

This research was supported by the National Natural Science Foundation of China (81490533, 81770075, 81800008, 91543114), National Program on Key Research Projects 
of China (2017YFC1310602), Shanghai Sailing Program (18YF1404300), Shanghai Clinical Key Disciplines Construction Project, Shanghai Top-Priority Clinical Key Disciplines Construction Project (2017ZZ02013), and The State Key Basic Research Program (973) project of China (2015CB553404).

\section{Availability of data and materials}

The datasets used or analysed during the present study are available from the corresponding author on reasonable request.

\section{Authors' contributions}

$\mathrm{DH}$ and MJ analysed the data and wrote the draft of the manuscript. YW, D Zhang, CZ did laboratory work. D Zhu, MZ, YS and $\mathrm{XC}$ designed the study, supervised the study and revised the manuscript. All authors read and approved the final manuscript.

\section{Ethics approval and consent to participate}

The present study was approved by the Ethics Committee of Zhongshan Hospital, Fudan University (Shanghai, China; approval no. 2011-212). Informed consent was obtained from all individual participants included in the study.

\section{Patient consent for publication}

Written informed consent for publication was obtained from all participants.

\section{Competing interests}

The authors declare that they have no competing interests.

\section{References}

1. Melsen WG, Rovers MM, Groenwold RH, Bergmans DC, Camus C, Bauer TT, Hanisch EW, Klarin B, Koeman M, Krueger WA, et al Attributable mortality of ventilator-associated pneumonia: A meta-analysis of individual patient data from randomised prevention studies. Lancet Infect Dis 13: 665-671, 2013.

2. Rello J, Ollendorf DA, Oster G, Vera-Llonch M, Bellm L, Redman R and Kollef MH; VAP Outcomes Scientific Advisory Group: Epidemiology and outcomes of ventilator-associated pneumonia in a large US database. Chest 122: 2115-2121, 2002.

3. Chastre J and Fagon JY: Ventilator-associated pneumonia. Am J Respir Crit Care Med 165: 867-903, 2002.

4. Kuti EL, Patel AA and Coleman CI: Impact of inappropriate antibiotic therapy on mortality in patients with ventilator-associated pneumonia and blood stream infection: A meta-analysis. J Crit Care 23: 91-100, 2008.

5. Kalil AC, Metersky ML, Klompas M, Muscedere J, Sweeney DA, Palmer LB, Napolitano LM, O'Grady NP, Bartlett JG, Carratala J, et al: Management of adults with hospital-acquired and ventilator-associated pneumonia: 2016 clinical practice guidelines by the infectious diseases society of America and the American Thoracic Society. Clin Infect Dis 63: e61-e111, 2016.

6. Wu CJ, Chen YP, Wang HC, Su IJ, Ko WC, Chen JS, Cheng CN, Lee NY, Sun HS, Chi CY and Chen TY: Identification of fungal pathogens from clinical specimens using multi-locus PCR coupled with electrospray ionization mass spectrometry. Diagn Microbiol Infect Dis 78: 141-143, 2014.

7. Peeters B, Herijgers P, Beuselinck K, Peetermans WE, Herregods MC, Desmet S and Lagrou K: Comparison of PCR-electrospray ionization mass spectrometry with 16S rRNA PCR and amplicon sequencing for detection of bacteria in excised heart valves. J Clin Microbiol 54: 2825-2831, 2016.
8. Ruiz M, Torres A, Ewig S, Marcos MA, Alcon A, Lledo R, Asenjo MA and Maldonaldo A: Noninvasive versus invasive microbial investigation in ventilator-associated pneumonia: Evaluation of outcome. Am J Respir Crit Care Med 162: 119-125, 2000.

9. Kaleta EJ, Clark AE, Johnson DR, Gamage DC, Wysocki VH, Cherkaoui A, Schrenzel J and Wolk DM: Use of PCR coupled with electrospray ionization mass spectrometry for rapid identification of bacterial and yeast bloodstream pathogens from blood culture bottles. J Clin Microbiol 49: 345-353, 2011.

10. Jacob D, Sauer U, Housley R, Washington C, Sannes-Lowery K, Ecker DJ, Sampath R and Grunow R: Rapid and high-throughput detection of highly pathogenic bacteria by Ibis PLEX-ID technology. PLoS One 7: e39928, 2012.

11. Jordana-Lluch E, Gimenez M, Quesada MD, Rivaya B, Marco C, Dominguez MJ, Armestar F, Martro E and Ausina V: Evaluation of the broad-range PCR/ESI-MS technology in blood specimens for the molecular diagnosis of bloodstream infections. PLoS One 10: e0140865, 2015

12. Sircar M, Ranjan P, Gupta R, Jha OK, Gupta A, Kaur R, Chavhan N, Singh M and Singh SK: Impact of bronchoalveolar lavage multiplex polymerase chain reaction on microbiological yield and therapeutic decisions in severe pneumonia in intensive care unit. Crit Care 31: 227-232, 2016.

13. Toma I, Siegel MO, Keiser J, Yakovleva A, Kim A, Davenport L, Devaney J, Hoffman EP, Alsubail R, Crandall KA, et al: Single-molecule long-read $16 \mathrm{~S}$ sequencing to characterize the lung microbiome from mechanically ventilated patients with suspected pneumonia. J Clin Microbiol 52: 3913-3921, 2014.

14. Guembe M, Marin M, Martin-Rabadan P, Echenagusia A, Camunez F, Rodriguez-Rosales G, Simo G, Echenagusia M and Bouza E; GEIDI Study Group: Use of universal 16S rRNA gene PCR as a diagnostic tool for venous access port-related bloodstream infections. J Clin Microbiol 51: 799-804, 2013.

15. Morozumi M, Nakayama E, Iwata S, Aoki Y, Hasegawa K, Kobayashi R, Chiba N, Tajima T and Ubukata K: Simultaneous detection of pathogens in clinical samples from patients with community-acquired pneumonia by real-time PCR with pathogen-specific molecular beacon probes. J Clin Microbiol 44: 1440-1446, 2006.

16. Ullberg M, Luthje P, Molling P, Stralin K and Ozenci V: Broad-range detection of microorganisms directly from bronchoalveolar lavage specimens by PCR/electrospray ionization-mass spectrometry. PLoS One 12: e0170033, 2017.

17. Stralin K, Ehn F, Giske CG, Ullberg M, Hedlund J, Petersson J, Spindler C and Ozenci V: The IRIDICA PCR/electrospray ionization-mass spectrometry assay on bronchoalveolar lavage for bacterial etiology in mechanically ventilated patients with suspected pneumonia. PLoS One 11: e0159694, 2016.

18. Huttner A, Emonet S, Harbarth S, Renzi G, Kaiser L and Schrenzel J: Polymerase-chain reaction/electrospray ionization-mass spectrometry for the detection of bacteria and fungi in bronchoalveolar lavage fluids: A prospective observational study. Clin Microbiol Infect 20: O1059-O1066, 2014.

19. Zakharkina T, Martin-Loeches I, Matamoros S, Povoa P, Torres A, Kastelijn JB, Hofstra JJ, de Wever B, de Jong M, Schultz MJ, et al: The dynamics of the pulmonary microbiome during mechanical ventilation in the intensive care unit and the association with occurrence of pneumonia. Thorax 72: 803-810, 2017.

20. Douglas IS, Price CS, Overdier KH, Wolken RF, Metzger SW, Hance KR and Howson DC: Rapid automated microscopy for microbiological surveillance of ventilator-associated pneumonia. Am J Respir Crit Care Med 191: 566-573, 2015.

21. Bacconi A, Richmond GS, Baroldi MA, Laffler TG, Blyn LB, Carolan HE, Frinder MR, Toleno DM, et al: Improved sensitivity for molecular detection of bacterial and Candida infections in blood. Journal of clinical microbiology 52 (9):3164-3174. doi:10.1128/JCM.00801-14, 2014

This work is licensed under a Creative Commons Attribution-NonCommercial-NoDerivatives 4.0 International (CC BY-NC-ND 4.0) License. 